\title{
Diagnosing the technical condition of modern diesel injectors using thermal infrared cameras
}

\author{
Marek Idzior $^{1}$ and Wojciech Karpiuk $^{1^{*}}$ \\ ${ }^{1}$ Poznan University of Technology, Institute of Combustion Engines and Powertrains, 61-138 Poznań, \\ Piotrowo 3, Poland
}

\begin{abstract}
Fuel injectors are the most damage-sensitive component of the diesel fuel injection system in self-ignition engines. Therefore, an important issue is their diagnosis for the proper assessment of their wear condition. The paper presents a method involving the use of an image from a thermal imaging camera to assess the technical condition of injectors used in common rail injection systems. Four injectors, whose technical condition was known, were tested. Three of them were characterized by a common fault - they had damaged control valve seats, while one of the injectors was fully functional. In order to precisely assess their technical condition, the injectors were tested on a test bench. While the injectors were working, the temperature of the body in the place of the control valve was measured at a constant time interval. The conducted research has shown that there is a relationship between the rate of temperature rise of the damaged injectors' body and their maximum temperatures, and the injection dose expenditure and the overflow expenditure.
\end{abstract}

\section{Introduction}

The internal combustion engine is one of the emitters of environmental pollutants, especially its atmosphere. The observed tendencies in the development of internal combustion engines, related to the consequences of the requirements of energy management, concern limiting the emission of $\mathrm{CO} 2$, the decrease of which is possible by drastic reduction of fuel consumption by these engines. Emission of toxic components of exhaust gases depends mainly on efficiency of fuel combustion, which depends on preparation and condition of fuel mixture. The injector, and first of all its nozzle, is an element directly affecting the parameters of the prepared charge. By proper selection of the nozzle and shaping of its operational parameters it is possible to influence the state of the charge and consequently the course of fuel combustion in a piston engine.

The common rail (CR) injection system commonly used today provides a more favorable injection pattern at lower fuel pressures than other injection systems due to the rectangular and dose-divided injection pattern achieved by maintaining a nearly constant pressure in the reservoir. This system makes it possible to select an individual dose of fuel for each cylinder while meeting the condition of quick response to changes in operating conditions of the

*Corresponding author:wojciech.karpiuk@put.poznan.pl 
engine. High injection pressure, achievable at low speed, allows to increase engine torque by 20 to $30 \%$. Eliminating the mechanical and hydraulic constraints of the conventional system makes it possible to increase the permissible speed. Application of CR system leads to reduction of fuel consumption and emission of toxic compounds contained in exhaust gases and increase of engine power.

A CR system with a high-pressure pump allows specific pressures to be achieved across the entire engine performance curve. The high-pressure pump operates in volumetric control mode, i.e. for each subsequent injection the dose and specified injection pressure is selected. This also provides new possibilities in fuel metering control. The use of a processor to control the system enables precise division of the injected fuel dose (pilot, main and injection). While the pilot dose contributes mainly to reducing engine noise (reduced auto-ignition delay period), the repetition makes it possible to reduce nitrogen oxide emissions using DeNOx catalytic reactors [1]. Technologies based on plasma technology and based on modifiers, added to the fuel, where its particular functions would act as a reducing agent, are also envisaged.

Fuel injectors are the most sensitive to damage parts of the fuel injection system. Therefore, the correct assessment of the state of their wear is an important issue. The analysis of vehicle operation data allows us to note that in $70-80 \%$ of cases the cause of improper functioning of compression-ignition engines are faulty injectors. In order to assess the correct functioning of the power supply system of these engines, the information obtained during the observation of the engine work and the results of measurements of individual parameters are used.

During general engine condition tests, checks are performed to assess the correct functioning of the engine. These include:

- inspection of ease of engine starting,

- measurement of engine power,

- check of the uniformity of engine operation,

- evaluation of the noise level of the engine,

- evaluation of smoke emission.

All of the above symptoms may be caused by a number of overlapping factors, which, however, consist of one basic factor - improper operation of injectors. A prerequisite for the maintenance of the device in a state of efficiency is a continuous diagnosis and prognosis of its condition. Therefore, a method based on using images from a thermal imaging camera to assess the technical condition of injectors used in common rail injection systems was proposed. This non-invasive, relatively easy to apply method can be successfully used for preliminary diagnostics of fuel injectors referring to both the assessment of their technical condition and preliminary selection of injectors [2].

\section{Purpose of the study}

The main objective of this research work was to analyze the technical condition of the electromagnetic injector using a thermal imaging camera. On the basis of the measured value of the parameter - the temperature of the injector body in a specific point (Figure 1), the change of temperature gradient depending on the duration of its work was analyzed. The differences of the injector body temperatures between the injector with the damaged control valve unit and the fully working injector were determined during the analysis. 

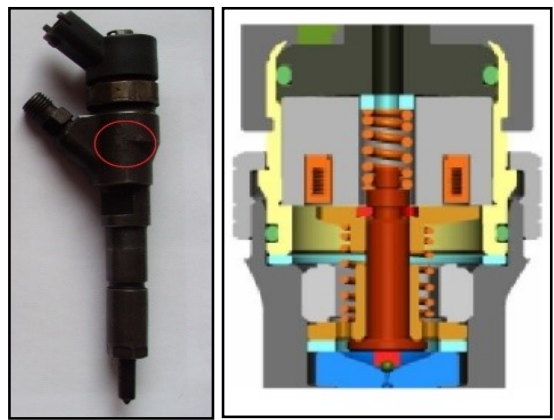

Fig.1. The location on the injector where the control valve is located (red border) and the design of the control valve [3].

The second practical goal was to develop a method for diagnosing faults in electromagnetic injectors without their partial disassembly. The current repair technology provides the following procedure [3]:

a) checking the injector on a test table

b) dismantling of the injector

c) cleaning of the parts

d) visual verification of the parts

e) replacement of damaged parts (or regeneration)

f) reassembly

g) checking on the test table.

An experienced diagnostician, while assessing the correct operation of the engine, may assume possible causes of faults. However, it may not always be able to accurately determine the source of their origin. The workshop practice clearly shows that replacing elements with new ones does not always bring positive results, which is confirmed by one of the authors' assumptions - in many cases the repair is based on the trial and error method.

\section{Test objects and research stand}

The first generation injectors manufactured by Bosch were used as test subjects (Figure 2). Before starting the tests, the types of defects of actuators and precision pairs, which occur in the above-mentioned injectors, were categorized (Table 1). Due to the common occurrence of mechanical damage of the control valve ball seat surface, it was decided to perform controlled damage of this element. An example photograph showing damage to the ball seat is shown in Figure 3.

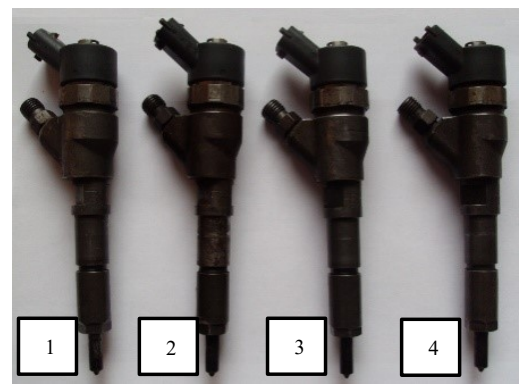

Fig.2. The location on the injector where the control valve is located (red border) and the design of the control valve [3]. 
Table 1.List of possible damages of elements and pairs of precise injectors.

\begin{tabular}{|c|c|c|}
\hline $\begin{array}{l}\text { TYPE OF } \\
\text { PART }\end{array}$ & $\begin{array}{c}\text { TYPE OF } \\
\text { MALFUNCTION }\end{array}$ & POSSIBLE CAUSES \\
\hline \multirow{3}{*}{ control valve } & seat damage & $\begin{array}{l}\text { excessive overflow rate; poor ball pitch; poor fuel } \\
\text { quality and contamination; improper filtration; } \\
\text { presence of solids (faulty pump) }\end{array}$ \\
\hline & $\begin{array}{l}\text { scratching of the stem } \\
\text { surface }\end{array}$ & $\begin{array}{l}\text { poor quality (lubricity) and contamination of the } \\
\text { fuel; poor filtration; presence of solids (faulty } \\
\text { pump) }\end{array}$ \\
\hline & $\begin{array}{l}\text { cracking of the high- } \\
\text { pressure ring }\end{array}$ & long-term operation of the engine \\
\hline \multirow{5}{*}{ nozzle } & $\begin{array}{c}\text { deformation of the well or } \\
\text { nest }\end{array}$ & $\begin{array}{l}\text { poor quality and contamination of the fuel; poor } \\
\text { filtration; presence of solids (faulty pump) }\end{array}$ \\
\hline & scratching the surface & as above \\
\hline & $\begin{array}{c}\text { the guiding surface is } \\
\text { seized }\end{array}$ & as above \\
\hline & $\begin{array}{l}\text { corrosion of the guiding } \\
\text { surface }\end{array}$ & poor fuel quality (sulfur and water content) \\
\hline & $\begin{array}{l}\text { overheating of contact } \\
\text { zones }\end{array}$ & $\begin{array}{l}\text { long-term and intensive operation of the engine; } \\
\text { too high operating temperature }\end{array}$ \\
\hline \multirow{5}{*}{ needle } & cone failure & $\begin{array}{l}\text { bad quality and contamination of fuel; improper } \\
\text { filtration; presence of solids (faulty pump) }\end{array}$ \\
\hline & scratching the surface & as above \\
\hline & seizure & as above \\
\hline & $\begin{array}{l}\text { corrosion of the guiding } \\
\text { surface }\end{array}$ & poor fuel quality (sulfur and water content) \\
\hline & $\begin{array}{l}\text { overheating of contact } \\
\text { zones }\end{array}$ & $\begin{array}{l}\text { long-term and intensive operation of the engine; } \\
\text { too high operating temperature }\end{array}$ \\
\hline
\end{tabular}

This resulted in a significant (uncontrolled) increase in fuel dose, which caused malfunction of the injectors. The tests were conducted on a test stand consisting of an electronic control module for a common-rail diesel engine, which was designed and manufactured by MechatronikaWyposażenieDydaktyczne Sp. z o.o.

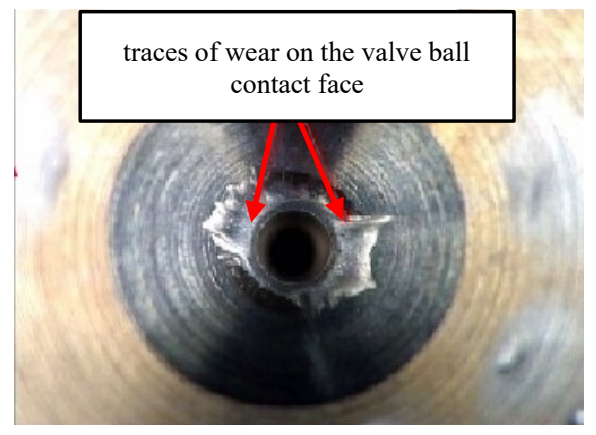

Fig.3. Control valve seat damage [3]. 
It consists of two basic modules:

- common rail system pump and injector control unit, used to demonstrate the operation and test the electrical and hydraulic parameters of the high-pressure pump and electromagnetic injector control system,

- common-rail diesel engine control unit with microprocessor controller, used to demonstrate and measure the parameters of the high-pressure pump and injector control system. The test stand is used to demonstrate the operation of the components and change the fuel dosage. The test bench allows for easy connection of measuring instruments to all sensors and actuators of the system, and the control of the pump drive allows simulation of the full speed range from the start-up phase to full speed.

The described stand, the view of which is presented in Figure 4, was adapted to the assumed tests. Pictures of the measurements were taken with the use of a FLIR T365 thermal imaging camera, which is equipped with the Laboratory of Combustion Engines of the Poznan University of Technology. The measurement of each injector lasted 15 minutes, and temperature changes were recorded every 15 seconds. The start of the measurement was considered to be the moment when the injectors were switched into operation mode using the EDC - common rail control module (Figure 5).

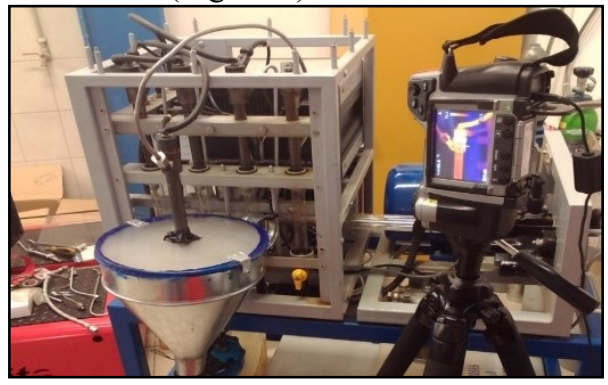

Fig.4.Test stand with mounted injector.

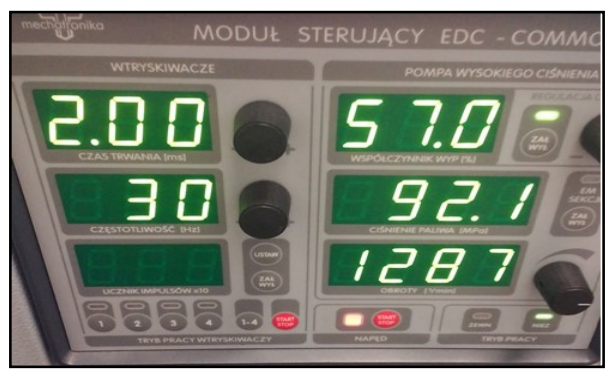

Fig.5. Injector operating parameters.

The characteristics of the selected injectors performed on the test table are shown in Figure 6 . The figure shows the characteristics of the damaged injector and the healthy injector.

Operating parameters were set equally for each injector:

a) fuel pressure: about $100 \mathrm{MPa}$

b) duration of injection: $2 \mathrm{~ms}$

c) rpm of high pressure pump: $1300 \mathrm{rpm}$

This is due to a malfunctioning control valve, by which fuel goes directly to the overflow. This situation occurs at the pressure of $130 \mathrm{MPa}$ and injection time of $1,300 \mu \mathrm{s}$. For a pressure of $25 \mathrm{MPa}$ and an injection time of $600 \mu \mathrm{s}$, the difference in dose is more pronounced. The fuel dose lower than that for an efficient injector by more than $22 \%$ can be explained by the fact that it is much harder to overcome the valve spring resistance at lower pressure. The third 
injector is characterized by too low fuel dose (by more than $12 \%$ ), as well as definitely too high amount of fuel that goes directly to the overflow - as much as 240 [ $\left.\mathrm{mm}^{3} / 1 \mathrm{inj}\right]$, which is $275 \%$. The fourth injector is within the allowed ranges of output and overflow.

Knowing the characteristics of the injectors and having the information on the injectors in which the control valve ball seats were damaged, it is possible to verify the validity of using thermal imaging methods to diagnose the technical condition of the injectors without dismantling them.

\section{Results and discussion}

The characteristics of the selected injectors performed on the test table are shown in Figure

6. The figure shows the characteristics of the damaged injector and the healthy injector.
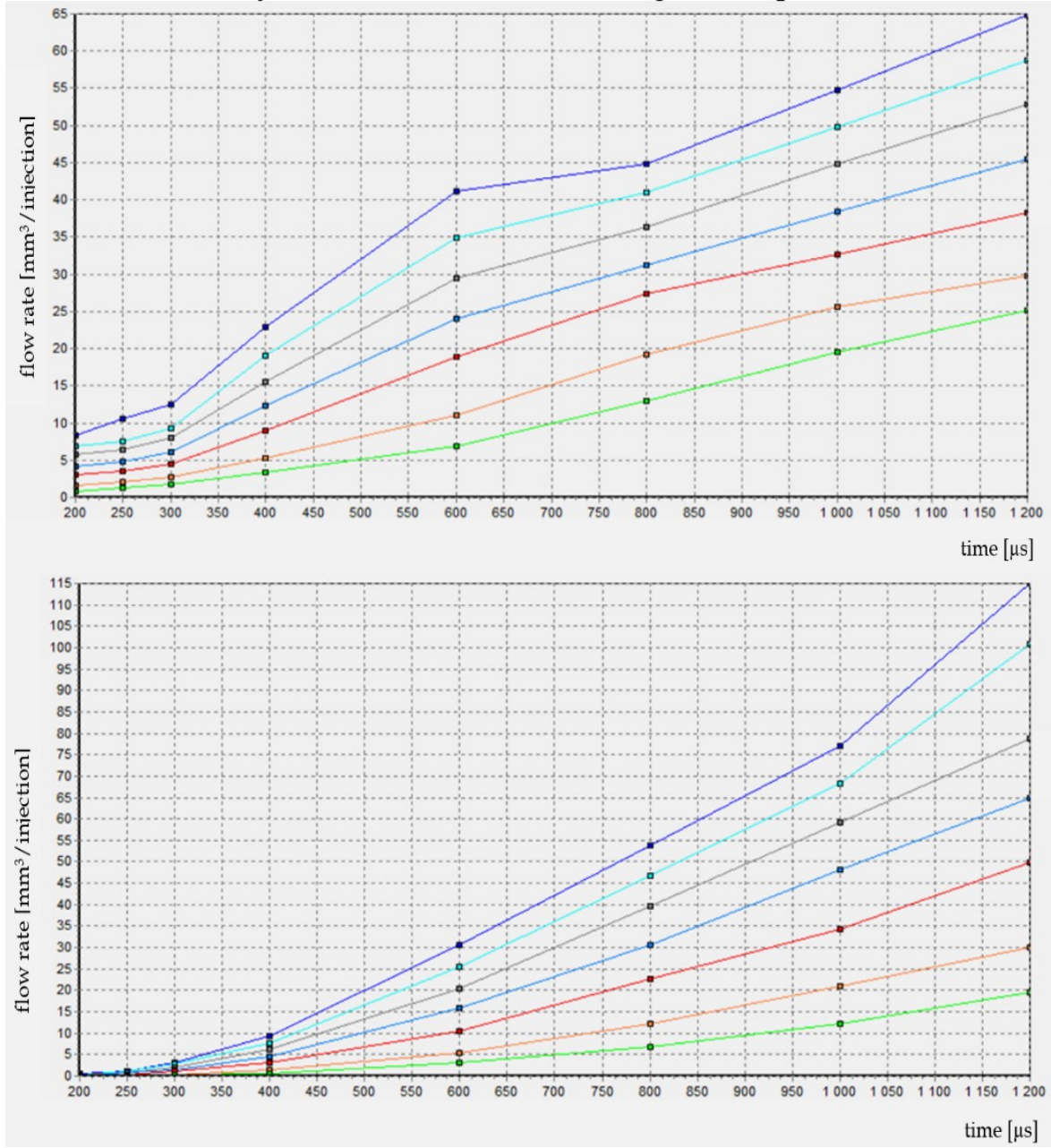

Fig.6. Characteristics of selected injectors made on test table (injector 3 - damaged; injector 4 working).

The measurements made it possible to make characteristics of the injectors (Tab. 2). 
Table 2. Characteristics of the injectors.

\begin{tabular}{|c|c|c|c|c|c|c|c|c|}
\hline No. & $\begin{array}{c}\text { injection } \\
\text { pressure } \\
{[\mathrm{MPa}]}\end{array}$ & $\begin{array}{l}\text { injection } \\
\text { time } \\
{[\mu \mathrm{s}]}\end{array}$ & $\begin{array}{l}\text { permissible } \\
\text { flow range } \\
\text { for one } \\
\text { injection } \\
{\left[\mathrm{mm}^{3} / \text { inj] }\right.}\end{array}$ & $\begin{array}{l}\text { type of } \\
\text { flow }\end{array}$ & $\begin{array}{c}\text { injector } \\
1\end{array}$ & $\begin{array}{c}\text { injector } \\
2\end{array}$ & $\begin{array}{c}\text { injector } \\
3\end{array}$ & $\begin{array}{c}\text { injector } \\
4\end{array}$ \\
\hline \multirow[t]{2}{*}{1} & \multirow[t]{2}{*}{130} & \multirow[t]{2}{*}{1300} & $\begin{array}{l}68,36- \\
75,64\end{array}$ & dose & 73 & 68 & 60 & 71 \\
\hline & & & 16-64 & overflow & 88 & 68 & 240 & 24 \\
\hline \multirow{2}{*}{2} & \multirow{2}{*}{25} & \multirow{2}{*}{600} & $2,52-5,48$ & dose & 3,00 & 1,96 & 5,40 & 3,50 \\
\hline & & & - & overflow & 18,00 & 9,00 & 54 & 6,75 \\
\hline \multirow{2}{*}{3} & \multirow{2}{*}{80} & \multirow{2}{*}{160} & $0,61-3,19$ & dose & 2,25 & 0,62 & 4,75 & 2,75 \\
\hline & & & - & overflow & 24,00 & 5,09 & 120 & 7,50 \\
\hline
\end{tabular}

The tested injectors were subjected to the same loads, under the same physical and chemical conditions. The total number of pictures taken makes it impossible to present them all in this paper, so some of them will be listed here.

The data series presented in Figure 7, showing the results of body temperature measurements of the tested injectors in the area of the control valve seat, allow us to notice the differences in the rate of heating of the tested injectors. In the case of injector 1 , it can be observed that it heats up to a temperature of about $70^{\circ} \mathrm{C}$ within the first minute of measurements. At the same time, the body temperature of injector 2 was about $65^{\circ} \mathrm{C}$. The highest temperature change in that period of time was observed for injector 3 . During the first minute of measurements, the body in the area of the control valve seat heated up to about $80^{\circ} \mathrm{C}$. The only working injector (No. 4) reached a temperature just close to $50^{\circ} \mathrm{C}$ during the first minute of testing.

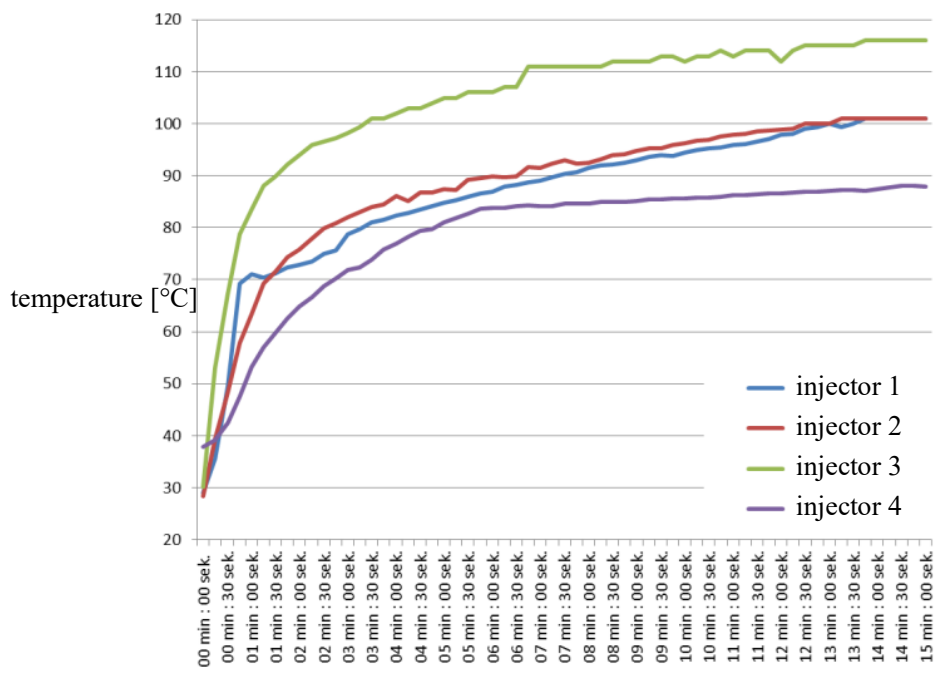

time [min]

Fig.7. Temperature change of the tested injectors body as a function of working time.

It should be noted that the last injector also had the highest temperature at the start of the test, which is further emphasized by the fact that its heating was the slowest. Similar correlations can be seen for half of the test duration. Over the next six minutes and thirty seconds of measurements, the temperature of the first injector increased by about $20^{\circ} \mathrm{C}$. 
For the second injector, the temperature rose by $30^{\circ} \mathrm{C}$ at the same time, to reach about $95^{\circ} \mathrm{C}$ in the middle of measurements.

After seven and a half minutes of operation, the body of injector no. 3 at the location of the control valve heated up to a temperature of over $110{ }^{\circ} \mathrm{C}$, which is an increase of $30{ }^{\circ} \mathrm{C}$ compared to the temperature it reached in the first minute of operation. The last injector at the specified time point reached a temperature of $85{ }^{\circ} \mathrm{C}$ which represents a temperature increase of about $35^{\circ} \mathrm{C}$.

The next time point at which the body temperature was analyzed is when the test ended. During a time interval of 15 minutes, injector number 1 reached a temperature slightly above $100{ }^{\circ} \mathrm{C}$. Injector number 2 also reached the same temperature, while injector number 3 reached $116^{\circ} \mathrm{C}$ at the end of the test, which was $6^{\circ} \mathrm{C}$ higher than at the halfway point. The last injector at the end of the test had a body temperature at the location of the control valve of $86^{\circ} \mathrm{C}$. Figures 8 and 9 show the change in body temperature, respectively, of the injector 4 (working) and 3 (damaged), visible during the measurements.
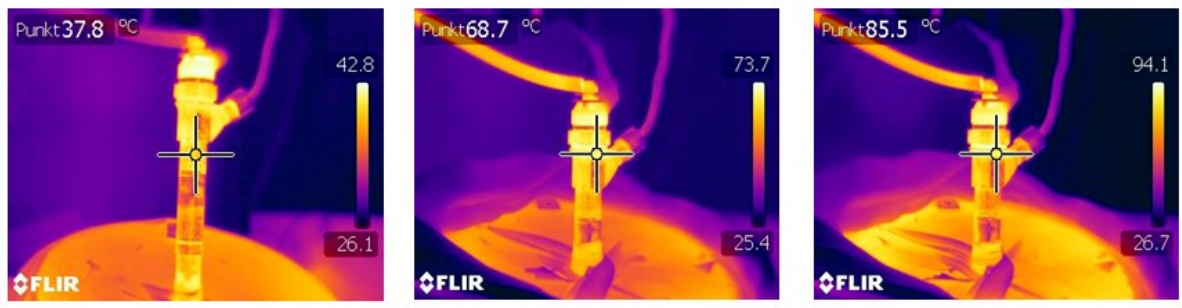

Fig.8. The change in body temperature - injector 4 .
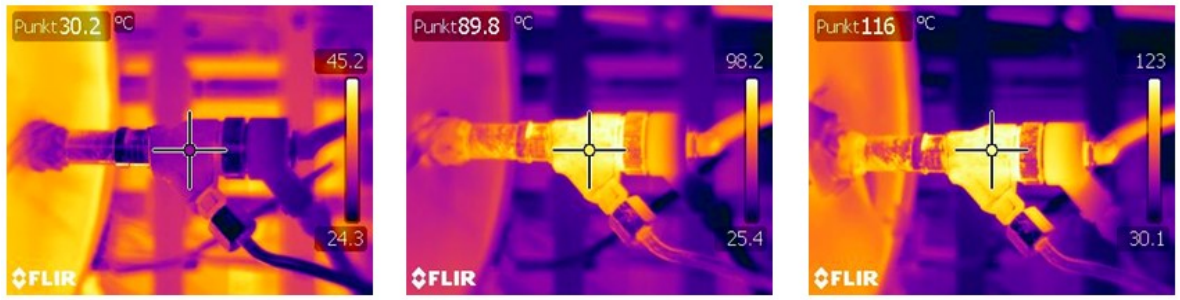

Fig.9. The change in body temperature - injector 3 .

\section{Summary}

The idea of assessing the technical condition of electromagnetic injectors by means of thermal imaging methods was born out of experience and workshop knowledge. An experienced mechanic is able to initially assess the technical condition of the injector on the basis of the temperature of its body. The conducted research proved that there is a dependency between the rate of temperature increase of the body of damaged injectors and their maximum temperatures, and the injection dose expenditure and the overflow expenditure. This regularity is visible in the results of the research presented in this paper, where the highest temperature and the shortest heating time were observed for the damaged injector number 3 , which was characterized by the largest deviations from the norm in the injection dose and the overflow dose. The lowest temperature as well as the longest heating time were observed in the case of injector No. 4, whose injection dose and overflow dose values were within the range permitted by the manufacturer. This allows the conclusion that as a result of damage 
to the control valve seat, more heat is released, which can be observed with the use of a thermal imaging camera, thus confirming the correctness of the proposed method.

\section{References}

1. O. Kröcher, D. Peitz, T.Sattelmayer, P. Toshev, G. Wachtmeister, A. Heubuch, B. Schulz, C. Gerhart, H.-P. Krimmer, B. Hammer, E. Jacob, Development of a $3 \mathrm{rd}$ Generation SCR NH 3 -Direct Dosing System for Highly Efficient DeNOx, SAE Int. J. Engines 5(3):938-946, 2012

2. M. Idzior, Problemy doboru wtryskiwaczy silników o zapłonie samoczynnym zasilanych paliwami alternatywnymi, WNiTE, 2012, Poznań

3. CSM Kędzia, training materials 